\title{
François Vouga, La religion crucifiée. Essai sur la mort de Jésus
}

Genève, Labor et Fides, coll. « Essais bibliques », 2013, 200 p.

\section{Daniel Vidal}

\section{(2) OpenEdition \\ Journals}

\section{Édition électronique}

URL : http://journals.openedition.org/assr/25667

DOI : $10.4000 /$ assr. 25667

ISSN : $1777-5825$

Éditeur

Éditions de l'EHESS

Édition imprimée

Date de publication : 30 décembre 2013

Pagination : 305

ISSN : 0335-5985

Référence électronique

Daniel Vidal, «François Vouga, La religion crucifiée. Essai sur la mort de Jésus », Archives de sciences sociales des religions [En ligne], 164 | 2013, mis en ligne le 14 mars 2014, consulté le 21 septembre 2020. URL : http://journals.openedition.org/assr/25667 ; DOI : https://doi.org/10.4000/assr.25667

Ce document a été généré automatiquement le 21 septembre 2020.

(C) Archives de sciences sociales des religions 


\section{François Vouga, La religion crucifiée. Essai sur la mort de Jésus}

Genève, Labor et Fides, coll. « Essais bibliques », 2013, 200 p.

Daniel Vidal

\section{RÉFÉRENCE}

François Vouga, La religion crucifiée. Essai sur la mort de Jésus, Genève, Labor et Fides, coll. «Essais bibliques », 2013, 200 p. 
1 «Tout va et vient, comme s'il y avait échange constant d'une matière spirituelle comprenant choses et hommes, entre les clans et les individus, répartis entre les rangs, les sexes et les générations [...] Le lien par les choses est un lien d'âme, car la chose elle-même a une âme, est de l'âme ". Pourquoi solliciter ici, dans une lecture attentive de l'ouvrage du théologien consacré à la signification de la mort de Jésus, les données élémentaires de l'anthropologie du don présentées par Marcel Mauss? Sans doute pour célébrer cette rencontre entre le plus profond de la réflexion théologique sur la signification du don gratuit, et le plus avéré de ce que les sciences sociales, avec Maurice Godelier, appellent "l'énigme du don», et qui bouleverse radicalement l'économie de

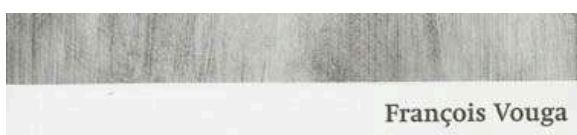

La religion crucifiée

Essai sur la mort de Jésus

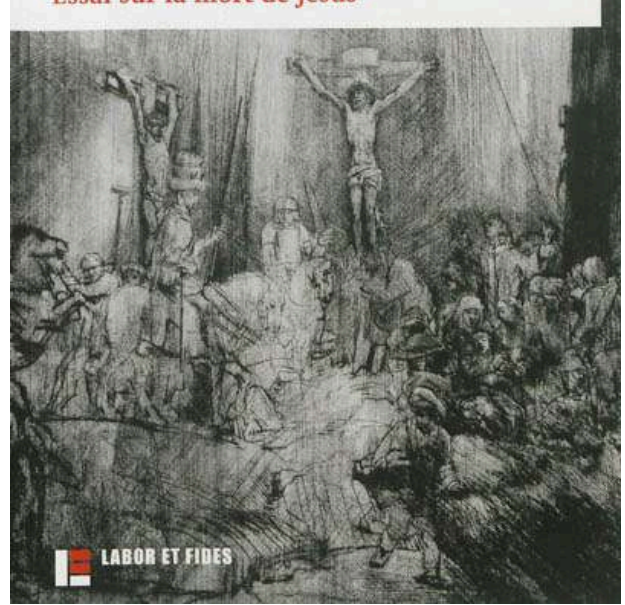
l'échange, de la dette et du salut. Tout sacrifice peut en effet valoir don - don de biens, don de soi. La mise à mort de Jésus relève-t-elle de cette interprétation sacrificielle? Jésus prenant en charge les péchés des hommes et, se substituant à eux, les libérant de leur poids et les disposant ainsi à la grâce divine? F. Vouga propose une lecture de cette mort en de tout autres termes. L'événement de la Croix et la personne du Crucifié signent « la fin de la religion comme médiation du salut et de la perdition entre Dieu et l'humanité ». Il faut désengager cette mort de la surimposition d'une " rationalité de la généralité ", subordonnée au principe de l'échange - échange du péché contre grâce de Dieu, à chacun selon sa repentance, etc. - et l'ouvrir à un autre ordre de rationalité, fondé sur "l'universalité et la gratuité ». Penser donc la crucifixion hors de toute consomption du péché de l'homme, et comme sa délivrance offerte pour «l'honneur de Dieu» - mais comme cet " événement absolument singulier » qui met en immédiate présence le «Père » et le sujet humain. Celui-ci alors pleinement reconnu responsable et libre, puisque participant de la "grâce divine » au-delà de toute économie de la "faute », et du rachat. Et dans le cadre immédiatement et universellement offert de la foi, cette "confiance gratuite faite de réciprocité et de reconnaissance». Alors toutes les distinctions et hiérarchies qui régissaient l'ordre de l'humain s'effacent. L'événement de la Croix concerne chacun en sa singularité et sa vocation à universalité. C'est en cela qu'il est écrit que le dieu s'est fait homme, et que tout homme est à raison du divin.

2 Le don ne peut ici s'entendre qu'au rebours de toute inscription marchande. Il est gratuit parce qu'il ne procède pas de la loi de l'échange, mais de la pure oblation de la grâce. Plus précisément, il est gratuit parce qu'il efface le principe même de la dette, et réamorce en permanence «l'obligation » de l'abandon réciproque et constant de dieu en la " créature », et de l'homme en son dieu. Pur don, pur amour. Certes, écrit l'auteur, le « créateur » est le nom de ce « tout-autre » que l'humanité s'est donné pour penser le dehors du monde, ou son fond. Mais il est aussi «puissance transcendante de 
transformation du quotidien ». La mort et la résurrection du dieu "fait homme» signent le basculement décisif du divin au principe même de l'humain. En d'autres termes, que le théologien énonce avec la volonté de bien marquer la rupture avec l'interprétation sacrificielle de la crucifixion, la mort de Jésus « est le fondement de la sécularisation », en ce qu'elle abolit la distinction du sacré et du profane. La laïcité trouve sa raison dans le texte même des Évangiles. Et les églises, leurs rites, leur idéologie de la souffrance salvatrice et de la faute inexpiable, n'ont pu établir leur puissance et leur «centralisme sacerdotal», que sur la négation de «l'universalisme évangélique » qu'il s'agit aujourd'hui de refonder.

3 L'enjeu est considérable et conduit François Vouga à revisiter textes et arguments. S'il rappelle qu'Abélard s'était opposé à l'interprétation de la mort de Jésus comme sacrifice expiatoire, et pour cela condamné comme hérétique, il confirme qu'Anselme de Cantorbéry fonda sa théologie sur l'argument du salut par le sacrifice de la croix. Ce sacrifice concernant l'humanité entière, et l'infini de ses péchés, seul un dieu pouvait l'offrir, s'y livrant. "Un être à la fois Dieu et homme, pour pourvoir lui-même à la réparation nécessaire ». Paradoxe de l'événement, et sa "nécessité rationnelle ». En ce sens, loin d'être cette singularité événementielle qui surgit comme force bouleversante dans l'existence de tout être humain, «le don que Jésus fait de sa vie rétablit au contraire, par une transaction immanente au système, la stabilité d'un équilibre originel». Si Luther convient en un premier temps que la crucifixion a permis de "régler la facture des transgressions ", s'il qualifie d'événement paradoxal la justice de Dieu - «celui qui est justice représente et concentre en même temps en lui tout le péché du monde »- le Réformateur s'écarte de la théologie du "salut racheté par la souffrance volontaire du Fils de Dieu». La folie de la Croix est cette rencontre absolument gratuite et toujours reconduite de Dieu et de l'universalité des humains, en une présence réciproque et singulière. Plus radical encore sera Calvin. Ce n'est pas la rédemption des péchés qui permet à l'amour divin de se répandre sur le peuple des croyants. L'amour "précède et prévient le péché humain ». L'Incarnation « n'est pas la conséquence du péché, elle est déjà présente dans l'acte de création ». Ainsi se trouve renversée l'image sacrificielle de la relation au divin. Car si le Christ est bien le médiateur entre Dieu et les hommes, ce n'est point comme victime expiatoire, mais au contraire comme «Fils » ouvrant l'accès au «Père ». La mort de Jésus n'a pas pour but de « restaurer l'honneur de Dieu » perdu par le péché des hommes. Toute malédiction " déprimée, rompue et dissipée ", écrit Calvin, cette mort fut " pour nous " - chacun, comme personne singulière, et tous, en leur universalité, ayant alors " accès à Dieu ». Cette mort contre toute Église, cette « confiance » contre tout rite, cette transcendance formulée comme « reconnaissance inconditionnelle des personnes ».

4 Contre la théologie sacrificielle de la Croix, François Vouga relit les Évangiles, Paul, Matthieu, Jean, Marc et les autres. Chacun, fragment après fragment, instituant une interprétation de la crucifixion comme récusation de toute médiation institutionnelle, dans cette rencontre de dieu et du sujet humain, cette personne désormais présente et révélée par la mort de Jésus. Une personne « irréductible à toute qualité observable ». D’où se déploie, chez Kierkegaard, le paradoxe de l'incarnation: "l'éternité de Dieu révélée dans une personne singulière ». Et aussi bien, pour F. Vouga, la transcendance comme révélation conjointe de dieu et de la personne humaine. En ce sens, dans l'oratorio Golgotha, «drame sacré » écrit en 1945-1948 par le compositeur suisse Frank Martin, l'auteur écoute/entend « la signification existentielle de la Passion », en quoi la mort de Jésus constitue cet « événement absolu » que le théologien analyse et consacre. 
La transcendance du «Royaume» doit désormais se comprendre comme celle "d'un dieu profane et laïque ». Il n'est alors de croyants que sous condition de s'affirmer "peuple laïque ». Réformation radicale de la théologie, protestation de la personne contre les médiations sacerdotales. Plaidoyer pour un "pur amour ", comme un don gratuit. Qui circule dans tout le champ de l'humain, et fait liaison sociale. Religion? Si l'on veut. Mais en son revers mystique, cet autre nom d'une "laïcité » venue à son accomplissement nécessaire. 